\title{
Progression of dynamic obstructions of the upper respiratory tract in 135 Thoroughbreds during exercise as cause of poor performance
}

\author{
Svenja Oellers', Ann Kristin Barton ${ }^{2}$ and Bernhard Ohnesorge ${ }^{3}$ \\ 1 Klinik für Pferde, Tierärztliche Hochschule Hannover; Pferdeklinik Burg Müggenhausen \\ 2 Klinik für Pferde, Freie Universität Berlin \\ ${ }^{3}$ Klinik für Pferde, Tierärztliche Hochschule Hannover
}

\begin{abstract}
Summary: The progression of dynamic obstructions of the upper respiratory tract in Thoroughbreds was examined by performing on-board exercise endoscopy during fast work on 135 horses. Exercise endoscopy was performed on horses with and without abnormal respiratory noise and with and without a history of poor performance. For classification, the exercise was divided into three equal sections. $54.8 \%(74$ horses) of the 135 horses examined had a history of poor performance; only $1.5 \%$ at the beginning of fast work and $35.5 \%$ at maximum performance. At the beginning of fast work, abnormal respiratory noise was audible in 8 horses (5.9\%), shortly before the end of training in 55 horses (40.7\%). A marked increase in the number of affected horses of each dysfunction among the horses with obstructions in the area of the upper respiratory tract could be observed with increasing performance. Some obstructions only occurred during higher performance levels. It could be demonstrated in which phase during horses' training obstructions occurred with or without having effect on the performance. The assessment of ACC showed which grade of ACC causes a negative impact on horses' performance in the different stages of exercise. As there is a high probability of poor performance at least during races with ACC of grade B3 or higher, treatment options can already be discussed here. As DDSP mainly occurs during maximum performance, it can only be definitely excluded if the horse is exercised to maximum performance during endoscopy. The evaluation method used in this study allows a better analysis of the effect of dysfunctions on each horse's performance, even if multiple obstructions occur.
\end{abstract}

Keywords: Thoroughbreds, dynamic obstructions of the upper respiratory tract, on-board exercise endoscopy, degree of performance, poor performance

Citation: Oellers S., Barton A. K., Ohnesorge B. (2020) Progression of dynamic obstructions of the upper respiratory tract in 135 Thoroughbreds during exercise as cause of poor performance. Pferdeheilkunde 36, 227-237; DOI 10.21836/PEM20200305

Correspondence: Svenja Oellers, Pferdeklinik Burg Müggenhausen, Heimerzheimerstr. 18, 53919 Weilerswist-Müggenhausen, Germany; svenja.oellers@web.de

Received: December 15, 2019 | Accepted: March 3, 2020

\section{Introduction}

Dynamic obstructions of the upper respiratory tract are among the most common causes of poor performance in racehorses. In addition, abnormal respiratory noise can be detected in a proportion of these horses (Morris and Seeherman 1991, Stick et al. 1992, Kannegieter and Dore 1995, Martin et al. 2000, Dart et al. 2001, Lane et al. 2006 a, b, Franklin 2008, Van Erck-Westergren et al. 2013, Franklin and Allen 2017).

Exercise endoscopy is the diagnostic tool of choice for examination of those horses. (Morris and Seeherman 1991, Kannegieter and Dore 1995, Hammer et al. 1998, Rosenstein and Stick 1999, Martin et al. 2000, Dart et al. 2001, Parente et al. 2002, Franklin 2008, Lane et al. 2006 a, b, Barakzai and Dixon 2011, Kelly et al. 2013, Allen et al. 2016, Franklin and Allen 2017, Hackett and Leise 2019). The procedure is performed subsequent to a previous endoscopy at rest, only thus enabling the detection of all potentially dynamic airway obstructions. By performing only endoscopy at rest, a dynamic airway obstruction cannot be excluded (Hackett et al. 1994, Kannegieter and Dore 1995, Hammer et al. 1998, Dart et al. 2001, Franklin 2008, Lane et al. 2006, a, b, Barakzai and Dixon 2011, Kelly et al. 2013).

In the past, exercise endoscopy has only been performed on a treadmill (Morris and Seeherman 1991, Stick et al. 1992, Kannegieter and Dore 1995, Rosenstein and Stick 1999, Dart et al. 2001, Lane et al. 2006 a, b, Allen et al. 2016, Allen and Franklin 2010). However, training and racing conditions and therefore also reaching the performance limit of the horse is easier with an on-board endoscope. Thereby, exercise endoscopy can be performed while the horses do their full-speed workout on their home racecourse. The horse can be ridden by its jockey and worked in its training group together with other horses. (Evans 2004, Franklin et al. 2008, Pollock and Reardon 2009, Desmaizieres et al. 2009, Sloet van Oldruitenborgh-Oosterbaan and Clayton 1999, Tamzali et al. 2008, Couroucé et al. 1999, Allen and Franklin 2010, 
Allen et al. 2011, Van Erck 201 1, Priest et al. 2012, Franklin and Allen 2017, Hackett and Leise 2019).

During races, Thoroughbreds are pushed to the performance limit of their airways. Therefore, even the smallest obstruction of airflow can influence performance. The severity of manifestation of obstructive diseases varies, depending on the performance phase in which they occur for the first time. Accurate observation of the point when upper airway obstruction occurs during training process therefore results in a better assessment of its effect on the horse's performance. This could allow a differentiation whether clinical findings affect a horse during the entire training or only during maximum performance and individual treatment options could be derived from it.

The aim of this study was to describe upper respiratory tract obstructions in Thoroughbreds in relation to the degree of their performance. In particular, the onset and progression of obstructions of the upper respiratory tract during a training session, i.e. during different levels of the horses' performance, should be monitored. Thus, by precise assignment, at which level of performance obstructions appear, the degree of the disease and its impact on the performance of the horse should be better assessable.

\section{Materials and Methods}

\section{Horses}

For this study, 135 Thoroughbred horses in training for racing were examined. The horses were examined at the respective racetrack of their training yard.

In terms of physical fitness, all examined horses were capable of participating in the daily training routine. No lamenesses, cardiovascular diseases, diseases of the lower respiratory tract or other diseases were known for these horses. Horses which had been subjected to surgery of the upper airways according to clinical history were excluded from the study. Whether or not the examined horses had already raced was not used as a selection criterion for this study.

Exercise endoscopy was performed on horses with and without respiratory noise and with and without a history of poor performance. For this purpose, on the one hand, the coach of each horse was interviewed regarding the performance of the horse in his training. On the other hand, the jockey of the horse was questioned directly after his ride. In case of noticed restrictions those were specified regarding the exact moment of their occurrence. Both coach and jockey were asked to classify the lack of performance into slight loss (nevertheless very noticeable), strong (capabilities of the horse greatly reduced), or whether there was a sudden slump in performance or whether poor performance might only be noticeable in the race.

The examiner checked for the presence of abnormal respiratory noise in each horse at the beginning and the end of fast work at maximum performance respectively. Whether abnormal respiratory noise was already audible during medium training performance was based on information provided by the riding jockey.

\section{Endoscopy procedure}

Exercise endoscopy was performed during the normal course of morning training at the racing yard. For placement of the endoscope, the horse was usually just held by its rider and additionally fixated with a rope twitch.

The endoscope $(9.8 \mathrm{~mm}$ endoscope tube, DRS Equipment by Optomed, les Ulis, France, in saddlebags) was inserted into the ventral nasal passage of the horse and advanced to a position where the entire larynx of the horse could be easily assessed. The tip of the endoscope was tilted slightly dorsally in order to obtain an optimal image after stretching of the head and neck at a gallop. Recording commenced immediately after placement of the endoscope. Thus, an endoscopy at rest was recorded initially, followed by recording during the warm-up phase of the horse at walk and trot and finally the horse's fast work on the track at a gallop.

The length of the gallop was adapted to the age and training level of the horse and was usually between 1500 and 2000 meters. Length and speed of the gallop was selected so that a high level of performance was achieved.

\section{Evaluation}

Endoscopic evaluations for this study were performed after completion of all 135 endoscopies and blinded to case history and findings during examination. Recordings were assessed in real time, slow motion and frame by frame view. The beginning of endoscopy was evaluated as endoscopy at rest and compared with the part under exercise. For this, fast work was categorised into three phases and evaluated accordingly. For classification, the time between the beginning of fast work and the point when the horse was slowed down from maximum performance was divided into three equal sections. The first third of fast work, shortly after the horse starting to canter on the track, was evaluated as exercise beginning $(G 1)$. The second third was described as intermediate exercise (G2) during which the horse had absolved half of its fast work on the track. The last third of fast work on the track was labelled peak of exercise (G3). During this phase the horse's speed was increased once more before the horse was subsequently slowed down and taken back to a trot. Obstructions during cool-down canter of the horses were also recorded and included in the evaluation of this study as a fourth category (G4). Furthermore, it was noted if poor racing performance was reported. Thus, all obstructions of the upper respiratory tract were assessed according to the point in time and the grade at which they appeared.

Results of endoscopy at rest were classified according to the Havemeyer workshop grading system (Dixon et al. 2003). Under exercise, dynamic laryngeal collapse (ACC) was evalvated according to Rakestraw et al. 1991, modified according to Go 2013. At that, grades B of submaximal abduction and $C$ of dynamic collapse were further divided into three subgrades respectively. Axial deviation of the aryepiglottic fold (ADAF) was evaluated according to King et al. 2001 and dynamic pharyngeal collapse (PC) according to Boyle et al. 2006. Occurrence of a dorsal displacement of the soft palate 
(DDSP) was classified into rarely short $(<3 x / 10 \mathrm{sec})$, often short ( $>3 \mathrm{x} / 10 \mathrm{sec}$ ) and long to continuous ( $>8 \mathrm{sec}$ ) DDSP. The analysis and calculation of statistical values were performed using SPSS version 18. The significance threshold was set at $p<0.05$.

\section{Results}

For this study, exercise endoscopy was performed on 135 Thoroughbred horses in training of an average age of 3.5 years ( 2 to 9 years) and evaluated. There were 44 stallions, 48 mares and 43 geldings. Abnormal respiratory noise and/ or poor performance could be detected in $67.4 \%$ (91 horses) of the 135 horses examined; $82.4 \%$ (75 horses) of these horses showed obstructions of the upper respiratory tract.

44 horses (32.6\%) were without any clinical findings. In $53.3 \%$ (23 horses) of these horses, an obstruction in the area of the upper respiratory tract was detected.

Among the 135 horses examined, $54.8 \%$ (74 horses) showed poor performance; in $78.4 \%$ (58 horses) of those horses, obstructions of the upper respiratory tract was detected. $41.5 \%$ (56 horses) exhibited abnormal respiratory noise during exercise endoscopy. Obstruction of the upper respiratory tract was present in 100\% of these horses (Oellers et al. 2018).

Correlation between exercise phase and history of poor performance

For analysis of obstructions in relation to performance, it was noted in which gallop phase in training the poor performance has been conspicuous or whether it could have been only be noticed in the race. This was compared with the obstructions diagnosed and the point in time of their occurrence. 54.8\% (74 horses) of the 135 horses examined had a history of poor performance. According to pre-report information, only 2 horses $(1.5 \%)$ already showed poor performance at the beginning of fast work (see Table 1). During intermediate exercise, 19 horses $(14.1 \%)$ were stated to show poor performance and at peak of exercise, poor performance was reported for 48 horses (35.5\%) in the case history. Furthermore, poor performance during races was noted in 56 horses. However, at the time of examination not all horses had been presented at races. In addition, horses which had shown explicit poor performance during training were usually not raced any more (see Table 1).
At the beginning of fast work, shortly after starting to canter on the track, abnormal respiratory noise was audible in 8 horses (5.9\%); 26 horses (19.2\%) had abnormal respiratory noise during intermediate exercise; during peak of exercise, shortly before the end of training, abnormal respiratory noise was audible in 55 horses (40.7\%). One horse displayed abnormal respiratory noise only after slowing down.

\section{Arytenoid cartilage collapse (ACC)}

Out of the 98 horses with obstruction in the area of the upper respiratory tract, 11 horses (11.2\%) showed ACC. At the beginning of exercise, 9 of those horses (9.2\%) had ACC of grade B, i.e. with submaximal but stable abduction (see Table 2). One horse with ACC from intermediate exercise was able to completely abduct at the beginning of exercise whereas one other horse $(1 \%)$ already showed dynamic collapse of the left arytenoid cartilage which, however, still remained in a stable position $(\mathrm{Cl})$. During intermediate exercise, complete collapse of the left arytenoid cartilage to the median of the Rima glottidis (C2) was diagnosed in 2 horses (2\%). One of these horses showed poor performance in correlation with the appearance of these obstruction, whereas in the second horse, poor performance was only noted during peak of exercise. The 9 horses with grade B findings now showed a higher grade of obstruction; $6(6.1 \%)$ were now classified as grade B3. Poor performance was now noted in 3 out of these 6 horses. When evaluating peak of exercise during training, ACC of grade $\mathrm{C}$ were detected in 7 horses $(7.1 \%)$, all of which but one horse ( $\mathrm{Cl}$ ) now showed poor performance (see Table 2). Six of these horses had complete collapse of the left arytenoid cartilage: one collapsed to the median of the Rima glottidis (C2) and 5 collapsed past the median (C3). Furthermore, ACC of grade B were diagnosed in 4 horses during peak of exercise; two of these horses showed grade B3. One of the horses now showed poor performance, whereas in the second one it was only noted during races (see Table 2).

\section{Vocal fold diseases (VFD)}

Obstructions in the area of the vocal fold were already detected at the beginning of exercise at gallop in total of 13 horses (13.3\%). During intermediate exercise, there were 31 horses (31.6. \%) and during peak of exercise within fast work there were 48 horses (49\%) with vocal fold obstructions (see Table 3). Here, bilateral vocal cord collapse occurred during

Table 1 Pre-reported occurrence of poor performance in different phases of exercise in 135 horses | Vorberichtliches beschriebenes Auftreten einer Leistungsschwäche während der unterschiedlichen Trainingsphasen

\begin{tabular}{lcccccc}
\hline$\%(n)$ & Trot & G1 & G2 & G3 & G4 & Race \\
\hline None & $100(135)$ & $98.5(133)$ & $85.9(116)$ & $64.4(87)$ & $97.0(131)$ & $39.8(37)$ \\
Mild & - & $1.5(2)$ & $11.9(16)$ & $24.4(33)$ & $1.5(2)$ & $23.7(22)$ \\
Severe & - & - & $2.2(3)$ & $9.6(13)$ & $1.5(2)$ & $33.3(31)$ \\
Sudden Slump & - & - & - & $1.5(2)$ & - & $3.2(3)$ \\
Total & $100(135)$ & $100(135)$ & $100(135)$ & $100(135)$ & $100(135)$ & $100(93)$ \\
\hline
\end{tabular}

$\mathrm{G} 1=$ beginning of exercise; $\mathrm{G} 2$ = intermediate exercise; $\mathrm{G} 3=$ peak of exercise; $\mathrm{G} 4=$ cool down canter, still in galopp; $\mid$ G1 = Beginn der Arbeit, $\mathrm{G} 2=$ Mittlere Arbeit;

G3 = Arbeitshöhepunkt; G4 = Ausgaloppieren, nach Höchstgeschwindigkeit 
intermediate exercise in one horse (1\%) which had no history of poor performance although ADAF was detected as additional obstruction. In two horses (2\%), vocal cord collapse only occurred during peak of exercise; for both of them, poor performance was only noted during races. With the exception of one horse, unilateral vocal cord collapse always occurred in combination with left-sided ACC and axial deviation in the area of the right caudal Plica vocalis (ADPV). Poor performance was reported for 4 horses (4/8) with unilateral vocal fold collapse during intermediate exercise and for 7 horses $(7 / 10)$ during peak of exercise. In addition to its occurrence in combination with VCC, unilateral or bilateral ADPV was detected as isolated obstruction in a total of 31 horses. At that, the vocal cord remained fully stretched and showed no signs of deviation, whereas their corresponding caudal area of the vocal fold bulged medially like a sail. During intermediate exercise, poor performance was reported for 3 out of 19 horses, but only one of these three horses showed no other obstructions than ADPV. However, it has to be taken into account that in some cases ADPV occurred during intermediate exercise but could no longer be assessed during peak of exercise due to an additional VCC or DDSP. Out of the 26 horses with ADPV during peak of exercise, 15 horses also showed poor performance; in 5 of these horses, ADPV was the only obstruction (see Table 3).

\section{Axial deviation of the aryepiglottic fold (ADAF)}

At the beginning of fast work, ADAF was detected in 7 horses (7.1\%) (see Table 4). The one horse among them which had medium-grade of deviation already showed poor performance. In addition, DDSP was diagnosed in 3 out of these 7 horses (43\%) later during peak of exercise. During intermediate exercise, ADAF was already diagnosed in 29 horses (29.6\%). 11 out of these 29 horses (38\%) later developed DDSP in addition. Furthermore, poor performance was noted for 7 of these 29 horses at this stage, 4 (4/7) with additional DDSP. During peak of exercise, ADAF occurred in total of 51 horses (52\%). In 14 out of the 51 horses (28\%), later DDSP became visible; 3 of these horses

\begin{tabular}{|c|c|c|c|c|c|}
\hline Table 2 & Arytenoid cartilage collapse & orses | & Aryknorpelkollaps bei 98 & & \\
\hline$\%(n)$ & Trot & G1 & G2 & G3 & G4 \\
\hline RA & $56.1(55)$ & 89.8 (88) & 88.8 (87) & 88.8 (87) & $89.8(88)$ \\
\hline RB 1 & $39.8(39)$ & $5.1(5)$ & $3.1(3)$ & $2.0(2)$ & $5.1(5)$ \\
\hline RB 2 & 3.1 (3) & 3.1 (3) & - & - & $1.0(1)$ \\
\hline RB 3 & - & $1.0(1)$ & $6.1(6)$ & $2.0(2)$ & $2.0(2)$ \\
\hline RC 1 & $1.0(1)$ & $1.0(1)$ & - & $1.0(1)$ & $2.0(2)$ \\
\hline RC 2 & - & - & $2.0(2)$ & $1.0(1)$ & $1.0(1)$ \\
\hline $\mathrm{RC} 3$ & - & - & - & $5.1(5)$ & - \\
\hline PP & - & - & $36.4(4 / 11)$ & $63.6(7 / 11)$ & - \\
\hline
\end{tabular}

$\mathrm{n}=98,98$ out of 135 horses with obstruction in the area of the upper respiratory tract; PP (poor performance): \% ( $\mathrm{n}$ ) of horses with ACC at this point (PP in race not included); $\mathrm{G} 1$ = beginning of exercise; $\mathrm{G} 2$ = intermediate exercise; G3 = peak of exercise; G4 = cool down canter, still in galopp; RA: Arytenoid cartilage in full abduction; RB 1: Arytenoid cartilage in submaximal abduction, temporal complete abduction possible; RB2: Arytenoid cartilage mostly in submaximal abduction position, position stable, vibration of the vocal cord possible; RB3: Arytenoid cartilage mostly in submaximal abduction position, position stable, VCC and/or ADPV; RC1: Arytenoid cartilage does not show any movement, but position remains stable; RC2: Arytenoid cartilage is not abducted and collapses to the median of the rima glottis; RC3: Arytenoid cartilage is not abducted and collapses via the median of the rima glottis (complete collapse), according to Rakestraw 1991, mod. by Go $2013 \quad \mathrm{n}=98$, von 135 Pferden haben 98 eine Obstruktion im Bereich der oberen Atemwege; PP (Leistungsschwäche): \% (n) mit ACC zu diesem Zeitpunkt (Leistungsschwäche im Rennen nicht enthalten); G1 = Beginn der Arbeit, G2 = Mittlere Arbeit; G3 =Arbeitshöhepunkt; G4 =Ausgaloppieren, nach Höchstgeschwindigkeit. RA: Aryknorpel vollständig abduziert; RB 1: Aryknorpel submaximal abduziert, zeitweise vollständige Abduktion möglich; RB2: Aryknorpel meistens in submaximaler Stellung abduziert, Stimmbandvibration möglich; RB3: Aryknorpel meist in stabiler submaximaler Stellung abduziert, VCC und/oder ADPV; RC1: Aryknorpel zeigt keine Bewegung, Position bleibt stabil; RC2: Aryknorpel wird nicht abduziert und kollabiert bis zur Medianen der Rima glottis; RC3: Aryknorpel wird nicht abduziert und kollabiert über die Mediane der Rima glottis (kompletter Kollaps), nach Rakestraw 1991, mod. von Go 2013

Table 3 Vocal fold diseases (VFD) in 98 horses | Erkrankungen im Bereich der Stimmfalten bei 98 Pferden

\begin{tabular}{|c|c|c|c|c|c|}
\hline$\%(n)$ & Trot & G1 & G2 & G3 & G4 \\
\hline VCC left side & - & - & $1.0(1)$ & $1.0(1)$ & $1.0(1)$ \\
\hline VCC left side and ADPV right side & - & $2.0(2)$ & $7.1(7)$ & $9.2(9)$ & $3.1(3)$ \\
\hline ADPV one or both sides & $3.1(3)$ & $8.2(8)$ & 19.4 (19) & $26.5(26)$ & $9.2(9)$ \\
\hline VCC both sides & - & - & $1.0(1)$ & $3.1(3)$ & $1.0(1)$ \\
\hline Vibration of one or both vocal cords & $1.0(1)$ & $3.1(3)$ & $3.1(3)$ & $9.2(9)$ & $2.0(2)$ \\
\hline PP & - & - & $22.6(7 / 31)$ & $45.8(22 / 48)$ & - \\
\hline
\end{tabular}

VCC: vocal cord collapse, ADPV: axial deviation of the area of the caudal plica vocalis, $n=98,98$ out of 135 horses with obstruction in the area of the upper respiratory tract; PP (poor performance): \% (n) of horses with VFD at this point (PP in race not included); $\mathrm{G} 1=$ beginning of exercise; G2 = intermediate exercise; $G 3$ = peak of exercise; $G 4=$ cool down canter, still in galopp | VCC: Stimmbandkollaps, ADPV: axiale Deviation der kaudalen Plica vocalis, $n=98$, von 135 Pferden haben 98 eine Obstruktion im Bereich der oberen Atemwege; PP (Leistungsschwäche): \% ( $n$ ) mit Befunden im Bereich der Stimmfalten zu diesem Zeitpunkt (Leistungsschwäche im Rennen nicht enthalten); G1 = Beginn der Arbeit, G2 = Mittlere Arbeit; G3 = Arbeitshöhepunkt; G4 = Ausgaloppieren, nach Höchstgeschwindigkeit 
showed infrequent and 6 frequent intermittent displacement and 5 displaced permanently. Out of the 36 horses with a low-grade ADAF, 12 were also reported to show poor performance during peak of exercise. Among the 15 horses which here showed medium-grade ADAF, poor performance was noted in 8 horses. For 8 further horses with ADAF during peak of exercise, poor performance was reported only during races (see Table 4).

\section{Dorsal displacement of the soft palate (DDSP)}

At the beginning of fast work, DDSP was observed in 4 out of the 98 horses $(4.1 \%)$ with obstruction in the area of the upper respiratory tract (see Table 5). One horse, however, already showed permanent DDSP $(>8 \mathrm{sec}$ ) at the outset of fast work and was also reported to show poor performance already at this stage. During intermediate exercise, 4 horses showed frequent short DDSP and 3 horses had permanent DDSP. Among the 4 horses with frequent short DDSP, two already showed poor performance. However, for both of them DDSP was not the only obstruction at that stage. All 3 horses with permanent DDSP during intermediate exercise also showed poor performance here according to history. DDSP was once more not the only dysfunction diagnosed in these 3 horses (ADAF, PI and ADPV in addition). During peak of exercise, DDSP was diagnosed in
23 horses (23.5\%) (see Table 5). Thirteen horses now showed permanent DDSP up to a few minutes. In 9 of these horses, the displacement persisted after slowing down until breathing began to calm down. Two further horses which had shown frequent intermittent DDSP during peak of exercise displayed permanent after slowing down. Among the 13 horses with permanent DDSP ( $>8 \mathrm{sec}$ ) during peak of exercise, poor performance was also noted for 11 horses at that stage. Only 2 of these horses showed DDSP as the only obstruction; in all others, the DDSP was initiated by ADAF, palatal instability or ADPV. In the two horses with permanent DDSP during peak of exercise and without apparent poor performance to date, DDSP was the only diagnosed obstruction of the upper respiratory tract.

Thus, permanent DDSP lasting up to few minutes which was evaluated as the most severe form of DDSP in this study occurred only during peak of exercise or during cool-down canter in 12 out of 15 horses (80\%) with this obstruction (see Table 5).

\section{Palatal instability (PI)}

At the exercise beginning, 3 horses (3\%) showed a palatal instability of the soft palate; in 2 of these horses, DDSP became visible as well during peak of exercise (see Table 6).

Table 4 Axial deviation of the aryepiglottic fold, one/both sides (ADAF) in 98 horses | Axiale Deviation der Plica aryepiglottica, ein-/beidseitig bei 98 Pferden

\begin{tabular}{lccccc}
\hline$\%(n)$ & Trot & G1 & G2 & G3 & G4 \\
\hline Mild & - & $6.1(6)$ & $26.5(26)$ & $36.7(36)$ & $9.2(9)$ \\
Moderate & - & $1.0(1)$ & $3.1(3)$ & $15.3(15)$ & - \\
PP & - & $14.3(1 / 7)$ & $24.1(7 / 29)$ & $39.2(20 / 51)$ & - \\
\hline
\end{tabular}

$n=98,98$ out of 135 horses with obstruction in the area of the upper respiratory tract; PP (poor performance): \% ( $n$ ) of horses with ADAF at this point (PP in race not included): $\mathrm{G} 1=$ beginning of exercise; $\mathrm{G} 2=$ intermediate exercise; $\mathrm{G} 3=$ peak of exercise; $\mathrm{G} 4=$ cool down canter, still in galopp $\mid n=98$, von 735 Pferden haben 98 eine $O b$ struktion im Bereich der oberen Atemwege; PP (Leistungsschwäche): \% (n) mit ADAF zu diesem Zeitpunkt (Leistungsschwäche im Rennen nicht enthalten); Gl = Beginn der Arbeit, G2 = Mittlere Arbeit; G3 =Arbeitshöhepunkt; G4 = Ausgaloppieren, nach Höchstgeschwindigkeit

Table 5 Dorsal displacement of the soft palate (DDSP) in 98 horses | Dorsalverlagerung des Gaumensegels bei 98 Pferden

\begin{tabular}{|c|c|c|c|c|c|}
\hline$\%(n)$ & Trot & G1 & G2 & G3 & G4 \\
\hline Infrequent intermittent & $15.3(15)$ & $3.1(3)$ & $4.1(4)$ & $4.1(4)$ & $6.1(6)$ \\
\hline Frequent short & $3.1(3)$ & - & $4.1(4)$ & $6.1(6)$ & $5.1(5)$ \\
\hline Long & - & $1.0(1)$ & $3.1(3)$ & 13.3 (13) & $11.2(11)$ \\
\hline PP & - & $25.0(1 / 4)$ & $45.5(5 / 11)$ & $47.8(11 / 23)$ & - \\
\hline
\end{tabular}

$\mathrm{n}=98,98$ out of 135 horses with obstruction in the area of the upper respiratory tract; PP (poor performance): \% ( $\mathrm{n}$ ) of horses with DDSP at this point (PP in race not included); $\mathrm{G} 1$ = beginning of exercise; $\mathrm{G} 2=$ intermediate exercise; $G 3=$ peak of exercise; $G 4=$ cool down canter, still in galopp $\quad n=98$, von 735 Pferden haben 98 eine $O b$ struktion im Bereich der oberen Atemwege; PP (Leistungsschwäche): \% (n) mit DDSP zu diesem Zeitpunkt (Leistungsschwäche im Rennen nicht enthalten); G1 = Beginn der Arbeit, G2 = Mittlere Arbeit; G3 = Arbeitshöhepunkt; G4 =Ausgaloppieren, nach Höchstgeschwindigkeit

Table 6 Palatal instability (PI) in 98 horses | Palatale Instabilität bei 98 Pferden

\begin{tabular}{lccccc}
\hline$\%(n)$ & Trab & $G 1$ & $G 2$ & $G 3$ & G4 \\
\hline Infrequent & $11.2(11)$ & $2.0(2)$ & $5.1(5)$ & $15.3(15)$ & $4.1(4)$ \\
Frequent & - & $1.0(1)$ & $3.1(3)$ & $6.1(6)$ & $2.0(2)$ \\
PP & - & $33.3(1 / 3)$ & $25.0(2 / 8)$ & $57.1(12 / 21)$ & \\
\hline
\end{tabular}

$\mathrm{n}=98,98$ out of 135 horses with obstruction in the area of the upper respiratory tract; PP (poor performance): \% ( $\mathrm{n}$ ) of horses with Pl at this point (PP in race not included); $\mathrm{Gl}=$ beginning of exercise; $\mathrm{G} 2=$ intermediate exercise; $\mathrm{G} 3=$ peak of exercise; $\mathrm{G} 4=$ cool down canter, still in galopp $n=98$, von 135 Pferden haben 98 eine Obstruktion im Bereich der oberen Atemwege; PP (Leistungsschwäche): \% (n) mit Pl zu diesem Zeitpunkt (Leistungsschwäche im Rennen nicht enthalten); Gl = Beginn der Arbeit, G2 = Mittlere Arbeit; G3 = Arbeitshöhepunkt; G4 = Ausgaloppieren, nach Höchstgeschwindigkeit 
One of the 3 horses with PI already showed poor performance at this stage according to history; however, this horse also showed permanent DDSP. Out of the 8 horses (8.2\%) with PI during intermediate exercise, DDSP became visible in 5 horses during peak of exercise. In 2 of these 8 horses, poor performance was already noted during intermediate exercise. During peak of exercise, PI was detected in 21 horses (see Table 6). Here, DDSP was present in addition in 12 horses. One horse showed infrequent short displacements, 5 horses had frequent short displacements and permanent DDSP developed in 6 horses in fast work. A history of poor performance was reported at the same time for 12 out of the 21 horses with PI during peak of exercise. Among them, 2 horses had $\mathrm{PI}$ as the only obstruction of the upper respiratory tract; 9 horses were also diagnosed with DDSP and one other horse had ADAF in addition (see Table 6).

\section{Discussion}

\section{Poor performance}

The information provided by trainers and riders as to the time when poor performance occurred showed a marked rise in the number of horses affected with increasing performance. Thus, the number of horses which showed poor performance increased by $34 \%$ between the exercise beginning and peak of exercise. So far, poor performance has been classified as existent or non-existent and not by the time of appearance during gallopp, e. g. by Morris and Seeherman et al. 1991, Martin et al. 2000, Tan et al. 2005, Lane et al. 2006 a, b, Van Erck-Westergren et al. 2013, Franklin and Allen 2017. A further marked change was apparent for the information of the horses' performance during races. In some horses, poor performance became more apparent during races, in others it is only noted here for the first time. Overall, poor performance during races was reported for 56 horses. Horses which already showed noticeable poor performance during training were usually not presented at any races; furthermore, some horses had not yet raced due to their age. However, poor performance is often noticed for the first time during race. Obstructions which may only occur during the performance of race are difficult to reproduce even during hard training. In the present study, this could nevertheless be achieved by simulation of head-to-head race on the grass track.

Overall, this shows the difficulties that sometimes occur in the assessment of whether a horse has noticeable poor performance because it is based on the information of the coach and jockey. In addition, each horse has different possibilities, so poor performance can hardly be measured in absolute terms of speed, etc.. However, experienced coaches usually know their horses very well and are good at assessing them, which of course also includes parameters like sweat, respiratory rate and others that.

\section{Occurrence of each dysfunction}

When looking at the occurrence of each dysfunction among the horses with obstructions in the area of the upper respiratory tract, a marked increase in the number of affected horses could be observed with increasing performance. Some obstructions only occurred during higher performance levels. Furthermore, a considerable increase in the degree of obstruction was noted with increasing performance.

\section{ACC}

Left sided ACC were overall detected in a small proportion of horses with obstruction of the upper respiratory tract at gallop (11.2\%; 11/98 horses; Oellers et al. 2018, similar to Lane et al. 2006 a, Barakzai and Dixon 2011). At the beginning of fast work, ACC were already visible in 10 out of the total 11 horses. However, only one of these horses had a grade of $A C C$ up to grade C1, i.e. a still stable left arytenoid cartilage without any abduction movement. Nevertheless, poor performance was not noted in any of these 10 affected horses at this phase of exercise. When intermediate exercise was reached, dynamic left sided ACC was detected in 2 of these horses (C2) and during peak of exercise, 7 horses showed collapse of the left arytenoid cartilage (C1-3). Thus, the percentage of horses with the highest grade of ACC increases from $9 \%$ to $63.3 \%$ between exercise beginning and peak of exercise. For this dysfunction, the number of horses affected does not increase with increasing performance, but the degree of obstruction. This can easily be explained by the increasing negative intrapulmonary pressure generated by a higher work of breathing with increasing performance. Among others, this has already been described by Cook et al. 1988, Rakestraw et al. 1991, Lane et al. 2006 b, Franklin et al. 2008. At the same time, the results give a very good account of how different the horses can achieve and maintain the abduction of their left arytenoid cartilage, which indicates different levels of severity of this disease. In horses with left sided ACC, poor performance was first noted during intermediate exercise. Among them was one horse which already showed ACC at the time but also half of horses with obstructions grade B (B3) at this stage. During peak of exercise or during races respectively, all 9 horses with obstructions grade B3 or higher showed poor performance. This shows that ACC usually leads to poor performance of affected horses, but only at higher grade and with increasing performance. Here, this was the case starting from grade B3, the occurrence of left-sided vocal cord collapse and right-sided axial deviation in the area of the caudal Plica vocalis. It can thus be assumed that obstructive ACC of grade B3 or higher will lead to poor performance during peak of exercise or at least during races.

In $82 \%$ of cases, ACC at gallop occurred in combination with left-sided VCC and right-sided axial deviation in the area of the caudal Plica vocalis (ADPV), which in the course of training always appeared first. With increasing performance, the further increasing abduction deficit of the left cartilage became apparent. This shows the strong correlation of this dysfunction with obstructions in the area of the vocal folds. Lane et al. 2006 a, b also described that ACC were always diagnosed in combination with unilateral or bilateral vocal cord collapse. At that, the collapse of the left vocal cord is caused by abduction deficit of the left arytenoid cartilage with corresponding decrease in tension of the left vocal cord. Thus, the unilateral left-sided VCC is to be regarded as a precursor to 
ACC in $90 \%$ (9/10 horses) of cases in this study; as well as the concurrent right-sided ADPV, it is directly related to the ACC. Only one horse with a unilateral vocal cord collapse showed no correlation with ACC.

\section{VCC}

All other obstructions in the area of the vocal folds occurred without correlation to ACC. A bilateral vocal cord collapse only became apparent during intermediate and peak of exercise in the 3 cases which occurred in this study. The horse with bilateral vocal cord collapse during intermediate exercise showed no signs of poor performance at the time of examination. The two horses with this obstruction during maximum training effort had a history of poor performance only noticeable during races. Thus, the induced obstructive restriction of airflow only showed a marked effect at high effort levels and may be the cause of horse's poor performance even as sole finding. However, the number of horses showing these obstructions in this study was too small to be able to make an assertion as to their effect on the horse's performance.

With increasing training performance, the occurrence of unilateral or bilateral axial deviation in the area of the caudal Plica vocalis (Oellers et al. 2018) as obstruction increased in number from $8.5 \%$ to $26.5 \%$ up to the highest performance. In 15 out of the 26 horses with ADPV during peak of exercise, poor performance was noted at the same time. Overall, however, only 12 horses showed ADPV as the only obstruction; 5 of them showed poor performance at the time and further 2 during races. Despite these 7 horses with poor performance it is questionable that this is caused solely by ADPV, as the restriction of airflow caused by this deviation appears so small that it seems unlikely to be the only cause of poor performance in horse. However, in racehorses during peak of exercise, even the smallest restriction of airflow can have an effect on their performance. There are probably many horses where the cause of poor performance is attributed to the upper respiratory tract due to the respiratory noise caused by these obstructions; however, this may not be the actual or at least not the only cause of performance deficits.

\section{$A D A F$}

During training gallop, the occurrence of ADAF increases from $7.1 \%$ to $52 \%$; the prevalence of palatal instability rises from $3.1 \%$ to $21.4 \%$. Thus, in the majority of affected horses, these obstructions only become apparent during intermediate to peak of exercise, whereby they also show a marked increase in severity. On the one hand, this accounts for the large number of horses which were diagnosed with ADAF in this study in comparison to other studies. A prevalence between 5 and $55 \%$ was described by Kannegieter and Dore 1995, Martin et al. 2000, King et al. 2001, Tan et al. 2005 and Lane et al. 2006 a, Franklin and Allen 2017, Hackett and Leise 2019. However, poor performance was only noted at the time in 7 of the 29 horses with ADAF during intermediate exercise; out of them, only 3 horses had ADAF as only respiratory obstruction. During peak of exercise, poor performance at this stage was reported for 20 out of the 51 horses with ADAF; however, ADAF was the sole obstruction in only 3 of those horses. For further 8 horses with ADAF during peak of exercise, poor performance was only reported during races; in 6 of those horses, ADAF was the sole obstruction. In relation to the large number of horses with ADAF overall, the number of horses with ADAF as sole obstruction showing poor performance remained relatively low (17.6\%, 9/51). It is therefore disputable whether ADAF can be the sole cause of poor performance and of course depends on the severity of this obstruction. Other studies state ADAF to be the sole cause of poor performance in affected horses (Kannegieter and Dore 1995, Martin et al. 2000, King et al. 2001, Tan et al. 2005, Lane et al. 2006 a, Franklin 2008, Priest et al. 2012).

\section{DDSP}

When looking at the progression of DDSP during fast work of the horses affected in this study, the occurrence of the most severe form with permanent DDSP (>8 sec) is of particular interest. This highest grade of DDSP was not yet detected at trot in any of the horses. In one horse only, it became apparent at begin of training and in a further 2 horses during intermediate exercise, whereas 10 horses showed DDSP (>8sec) during peak of exercise and a further 2 after slowing down. Thus, in $80 \%$ of affected horses, this grade of DDSP only occurs towards the end of fast work at highest performance. 11 out of the 13 horses (85\%) with this abnormality had history of poor performance; it can therefore be assumed that it usually poses performance intolerance. Poor performance in these horses was always noted at the same time as permanent DDSP was diagnosed endoscopically. Even though the direct correlation between DDSP and poor performance has already been described, among others, by Martin et al. 2000, Franklin et al. 2002 and Lane et al. 2006 a, Parente 2018, Allen and Franklin 2013, the simultaneous occurrence of poor performance with the onset of DDSP could be impressively demonstrated in this study. Furthermore, the appearance of permanent DDSP with very short intermissions always persisted until the end of training. Infrequent and frequent intermittent DDSP occurred only during exercise beginning and intermediate exercise in 3 horses but were no longer visible during peak of exercise; thus, they had a small impact on performance at most. Almost all horses with infrequent and frequent intermittent DDSP remained free from poor performance. Thus, this form of DDSP can be assumed to have no major effect on performance.

Permanent DDSP often only occurs during high performance at maximum speed towards the end of training and can thus only be diagnosed endoscopically at that stage on the racetrack. Horses which show permanent DDSP already at the beginning of training are certainly much more severely affected as performance limitation sets in directly with appearance. Nevertheless, the final straight with further increase in the speed of racehorses is of great importance and here comes the collapse of the performance.

\section{Conclusion}

The evaluation according to horses' exercise phase with exact observation of when and how obstructions occur and develop in the course of fast work combined with exact performance 
reports by trainers and riders has proven to be a successful method in this study. It leads to a considerably improved assessment of the effects of the occurring obstructions on the horses' performance. It could be demonstrated at what stage during horses' training obstructions occurred with or without having effect on performance. The assessment of ACC showed from which grade of ACC and which exercise phase a negative impact on horses' performance was caused. As there is a high probability of poor performance at least during races with ACC of grade B3 or higher, treatment options can already be discussed here. For permanent DDSP (>8 sec), correlation with poor performance can be assumed due to the synchronicity between occurrence of obstruction and onset of poor performance. As DDSP mainly occurs during peak of exercise, it can only be definitely excluded if the horse is exercised to maximum performance during endoscopy. In this study, infrequent and even frequent intermittent displacements which do not develop into permanent displacements were not associated with poor performance. Thus, indication for surgery is to be questioned unless there is proof of longer displacements. In case of doubt, a further endoscopy is necessary to confirm the indication for surgery. Other studies have already shown that the endoscopic findings may change in the course of time. (McGivney et al. 2019). Unilateral VCC occurs in combination with ADPV in 9 out of 10 cases in this study. The unilateral VCC also developed into an ACC in 9 out of 10 cases. Furthermore, the obstructive airflow restriction caused by bilateral vocal cord collapse only leads to performance limitation at high effort levels. It could not be determined in this study to what extent ADPV could be the sole cause of poor performance in affected horses; this should be examined in further studies. For other obstructions such as Pl, ADAF and ADPV, correlation with poor performance has also not been sufficiently ascertained and depends on the degree of their occurrence. As sole finding, they are associated with poor performance only in few cases. Nevertheless, these are obstructions, which together with others may be responsible for poor performance of the affected horses. Overall, the evaluation method used in this study allows for better analysis of the effect of dysfunctions on each horse's performance, even if multiple obstructions occur. However, data regarding the horses' performance in this study is solely based on information provided by trainers and riders and could be further objectified.

\section{Acknowledgements}

The authors would like to thank the Burg Müggenhausen equine clinic for providing the on-board endoscope.

\section{Conflict of interest}

The authors report no conflict of interest.

\section{References}

Allen K. J., Franklin S. H. (2010) Comparisons of overground endoscopy and treadmill endoscopy in UK Thoroughbred racehorses. Equine Vet. J. 42, 186-191; DOI 10.1111/i.20423306.2010.00033.x
Allen K., Franklin S. (2013) The effect of palatal dysfunction on measures of ventilation and gas exchange in Thoroughbred racehorses during high intensity exercise. Equine Vet. J. 45, 350-354; DOI 10.1 111 / j.2042-3306.2012.00627.x

Allen K. J., Hillyer M. H., Terron-Canedo N., Franklin S. H. (2011) Equitation and exercise factors affecting dynamic upper respiratory tract function: a review illustrated by case reports. Equine Vet. Educ. 23, 361-368; DOI 10.1111/j.2042-3292.2010.00171.x

Allen K. J., van Erck-Westergren E., Franklin S. H. (2016) Exercise testing in the equine athlete. Equine Vet. Educ. 28, 89-98; DOI 10.1111 /eve. 12410

Barakzai S. Z., Dixon P. M. (2011) Correlation of resting and exercising endoscopic findings for horses with dynamic laryngeal collapse and palatal dysfunction. Equine Vet. J. 43, 18-23; DOI 10.1111/j.2042-3306.2010.00108.x

Boyle A. G., Martin B. B., Davidson E. J., Durando M. M., Birks E. K. (2006) Dynamic pharyngeal collapse in racehorses. Equine Vet. J. Suppl. 38, 546-550; DOI 10.1111/j.2042-3306.2006.tb05602.x

Couroucé A., Geffroy O., Barrey E., Auvinet B., Rose R. J. (1999) Comparison of exercise tests in French trotters under training track, racetrack and treadmill conditions. Equine Vet. J. Suppl. 30, 528532; DOI 10.1111/i.2042-3306.1999.tb05278.x

Dart A. J., Dowling B. A., Hodgson D. R., Rose R. J. (2001) Evaluation of high-speed treadmill videoendoscopy for diagnosis of upper respiratory tract dysfunction in horses. Aust. Vet. J. 79, 109-1 12; DOI 10.1111/j.1751-0813.2001.tb10713.x

Desmaizieres L. M., Serraud N., Plainfosse B., Michel A., Tamzali Y. (2009) Dynamic respiratory endoscopy without treadmill in 68 performance Standardbred, Thoroughbred and saddle horses under natural training conditions. Equine Vet. J. 41, 347-352; DOI 10.2746/042516409 × 427169

Dixon P. M., Robinson N. E., Wade J. F. (2003) Workshop summary. In: Proceedings of a Workshop on equine recurrent laryngeal neuropathy. Dixon P. M., Robinson N. E., Wade J. F. (eds.), R \& W Publications, Newmarket, 93-97

Franklin S. H. (2008) Dynamic collapse of the upper respiratory tract: A review. Equine Vet. Educ. 20, 212-224; DOI 10.2746/095777308X290382

Franklin S. H., Allen K. J. (2017) Assessment of dynamic upper respiratory tract function in the equine athlete. Equine Vet. Educ. 29, 92-103; DOI 10.1111/eve.12432

Go L., Barton A., Ohnesorge B. (2014) Objective classification of different head and neck positions and their influence on the radiographic pharyngeal diameter in sport horses. BMC Veterinary Research 10, 118; DOI 10.1186/1746-6148-10-118

Hackett E. S., Leise B. S. (2019) Exercising upper respiratory videoendoscopic findings of 50 competition draught horses with abnormal respiratory noise and/or poor performance. Equine Vet. J. 51, 370-374; DOI 10.1111/evj.13026

Hackett R. P., Ducharme N. G., Mitchell L. (1994) The role of treadmill endoscopy in diagnosis of dynamic obstruction of the upper airway. Proc. Am. Ass. Equine Practnrs 40, 83

Hammer E. J., Tulleners E. P., Parente E. J., Martin B. B. (1998) Videoendoscopic assessment of dynamic laryngeal function during exercise in horses with grade-III left laryngeal hemiparesis at rest: 26 cases (19921995). J. Am. Vet. Med. Assoc. 212, 399-403; DOI PMID: 9470052 Holcombe S. J., Derksen F. J., Stick J. A., Robinson N. E. (1999) Pathophysiology of dorsal displacement of the soft palate in horses. Equine Vet. J. Suppl. 31, 45-48; DOI 10.1111/i.20423306. 1999.tb05186.x

Kannegieter N. J., Dore M. L. (1995) Endoscopy of the upper respiratory tract during treadmill exercise: a clinical study of 100 horses. Aust. Vet. J. 72, 101-107; DOI 10.1111/i.1751-0813.1995.tb15020.x

Kelly P. G., Reardon R. J. M., Johnston M. S., Pollock P. J. (2013) Comparison of dynamic and resting endoscopy of the upper portion of the respiratory tract in 57 Thoroughbred yearlings. Equine Vet J. 45,700-704; DOI 10.1111/evj.12061

King D. S., Tulleners E. P., Martin B. B., Parente E. J., Boston R. C. (2001) Clinical experiences with axial deviation of the aryepiglottic folds in 52 racehorses. Vet. Surg. 30,151-160; DOI 10.1053/ jvet.2001.21389 
Lane J. G., Bladon B., Little D. R. M., Naylor J. R. J., Franklin S. H. (2006) Dynamic obstructions of the equine upper respiratory tract. Part 1: observations during high-speed treadmill endoscopy of 600 Thoroughbred racehorses. Equine Vet. J. 38, 393-399; DOI $10.2746 / 042516406778400583$

Lane J. G., Bladon B., Little D. R. M., Naylor J. R. J., Franklin S. H. (2006) Dynamic obstructions of the equine upper respiratory tract. Part 2: comparison of endoscopic findings at rest and during highspeed treadmill exercise of 600 Thoroughbred racehorses. Equine Vet. J. 38, 401-407; DOI 10.2746/042516406778400619

Lumsden J. M., Stick J. A., Caron J. J., Nickels F. A., Brown C. M., Godber L. M., Derksen F. J. (1995) Upper airway function in performance horses: videoendoscopy during high-speed treadmill exercise. Comp. Cont. Educ. 17, 1134-1143

Martin B. B., Reef V. B., Parente E. J., Sage A. D. (2000) Causes of poor performance of horses during training, racing, or showing: 348 cases (1992-1996). J. Am. Vet. Med. Assoc. 216, 554-558; DOI 10.2460/javma.2000.216.554

Morris E. A., Seeherman H. J. (1990) Evaluation of upper respiratory tract function during strenuous exercise in racehorses. J. Am. Vet. Med. Assoc. 196, 431-438; DOI PMID: 2298672

Morris E. A., Seeherman H. J. (1991) Clinical evaluation of poor performance in the racehorse: the results of 275 evaluations. Equine Vet. J. 23, 169-174; DOI 10.1111/i.2042-3306.1991.tb02749.x

McGivney C. L., Sweeney J., Gough K. F., Hill E. W., Katz L. M. (2019) Serial evaluation of resting and exercising overground endoscopic examination results in young Thoroughbreds with no treatment intervention. Equine Vet. J. 51, 192-197; DOI 10.1111/evi.12994

Oellers S., Barton, A., Ohnesorge, B. (2018) Frequencies of dynamic obstructions of the upper respiratory tract in 135 Thoroughbreds during on-board exercise endoscopy. Pferdeheilkunde 34 (3):223-231; DOI 10.21836/PEM20180302

Parente E. J. (1997) Treadmill endoscopy. In: Equine Endoscopy, Brown C. M., Traub-Dargatz J. L. (eds.), Mosby, St Louis, 2nd edn., 112

Parente E. J. (2018) Fifty years of recurring struggles with recurrent laryngeal neuropathy. Equine Vet. J. 50, 155-158; DOI 10.1111/evj.12763

Parente E. J., Martin B. B., Tulleners E. P., Ross M. W. (1994) Upper respiratory dysfunctions in the horse during high-speed treadmill exercise. Proc. Am. Ass. Equine Practnrs 40, 81-82

Parente E. J., Martin B. B., Tulleners E. P., Ross M. W. (2002) Dorsal displacement of the soft palate in 92 horses during high-speed treadmill examination (1993-1998). Vet. Surg. 31, 507-512; DOI 10.1053/ivet.2002.36009

Pigott J. H., Ducharme N. G., Mitchell L. M., Soderholm L. V., Cheetham J. (2010) Incidence of swallowing during exercise in horses with dorsal displacement of the soft palate. Equine Vet. J. 42, 732-737; DOI 10.1111/j.2042-3306.2010.00116.x

Pollock P. J., Reardon R. J. M., Parkin T. D. H., Johnston M. S., Tate J., Love S. (2009) Dynamic respiratory endoscopy in 67 Thoroughbred racehorses training under normal ridden exercise conditions. Equine Vet. J. 41, 354-360; DOI 10.2746/042516409X407107
Priest D. T., Cheetham J., Regner A. L., Mitchell L., Soderholm L. V., Tamzali Y., Ducharme N. G. (2012) Dynamic respiratory endoscopy of Standardbred racehorses during qualifying races. Equine Vet. J. 44, 529-534; DOI 10.1111/i.20423306.2012.00562.x

Rakestraw P. C., Hackett R. P., Ducharme N. G., Nielan G. J., Erb H. N. (1991) Arytenoid cartilage movement in resting and exercising horses. Vet. Surg. 20, 122-127; DOI 10.1111/j.1532950x.1991.tb00319.x

Robertson J. T. (1998) Dorsal displacement of the soft palate. In: Current Techniques in Equine Surgery and Lameness. White N. A., Moore J. N. (eds.), Saunders, Philadelphia, USA., 2nd edn., $131-135$

Sloet van Oldruitenborgh-Oosterbaan M. M., Clayłon H. M. (1999) Advantages and disadvantages of track vs. treadmill tests. Equine Vet. J. Suppl. 30, 645-647; DOI 10.1111/ן.2042-3306.1999. tb05305.x

Stick J. A., Derksen F. J., Nickels F. A., Brown C. M., Arden W. A., Fulton I. C., Peloso J. G. (1990) Upper airway videoendoscopy during exercise in poorly performing horses. In: Proceedings of the Annual Convention of the American Association of Equine Practitioners, 38, 431-438; DOI AGR: IND92053759

Stick J. A., Peloso J. G., Morehead J. P., Lloyd J., Eberhart S., Padungtod P., Derksen F. J. (2001) Endoscopic assessment of airway function as a predictor of racing performance in Thoroughbred yearlings: 427 cases (1997-2000). J. Am. Vet. Med. Assoc. 219,962-967; DOI 10.2460/javma.2001.219.962

Stick J. A., Tulleners E. P., Robertson J. T., Holcombe S. J. (1999) Larynx. In: Equine Surgery. Auer J. A., Stick J. A. (eds.), Saunders, Philadelphia, USA., 2nd edn., 349-368

Tamzali Y., Serraud N., Baup B., Desmaizieres L. M. (2008) How to perform endoscopy during exercise without a treadmill. In: American Association of Equine Practitioners, Proceedings of the $54^{\text {th }}$ AAEP Annual Convention 54, 24-28,

Tan R. H. H., Dowling B. A., Dart A. J. (2005) High-speed treadmill videoendoscopic examination of the upper respiratory tract in the horse: the results of 291 clinical cases. Vet. J. 170, 243-248; DOI 10.1016/j.tvil.2004.06.011

Van Erck E. (2011) Dynamic respiratory videoendoscopy in ridden sport horses: effect of head flexion, riding and airway inflammation in 129 cases. Equine Vet. J. 43, Suppl. 40, 18-24; DOI $10.1111 /$ j.2042-3306.2011.00492.x

Van Erck-Westergren E., Franklin S. H., Bayly W. M. (2013) Respiratory diseases and their effects on respiratory function and exercise capacity. Equine Vet. J. 45, 376-387; DOI 10.1111/ evj. 12028

Witte S. H. P., Witte T. H., Harriss F., Kelly G., Pollock P. J. (201 1) Association of owner-reported noise with findings during dynamic respiratory endoscopy in Thoroughbred racehorses. Equine Vet. J. 43,9-17; DOI 10.1111/i.2042-3306.2010.00152.x 